\title{
Vibration Control of Aircraft Semi-Active Suspension System using PID-Bees Technique
}

\author{
Ali Reza Toloei \\ Department of Aerospace \\ Shahid Beheshti University \\ Tehran, Iran
}

\author{
Milad Zarchi \\ Department of Aerospace \\ Shahid Beheshti University \\ Tehran, Iran
}

\author{
Behrooz Attaran \\ Department of Mechanic \\ Shahid Chamran University \\ Ahwaz, Iran
}

\begin{abstract}
The dynamic load and vibration caused by landing impact and the unevenness of runway will result in airframe fatigue, discomfort of crew/passengers and the reduction of the pilot's ability to control the aircraft. The semi-active suspension system can provide good performance of both landing impact and taxi, and has the ability for adapting to various ground and operational conditions. This current paper designs Proportional Integral Derivative controller based on Bees Intelligent Algorithm as the optimization technique for nonlinear model of semi-active landing gear system that chooses damping performance of system at touchdown as object function. Optimal setting of controller parameters to achieve favorable time response using numerical software method based on Bees Algorithm is more simple and more effective than other traditional methods such as Ziegler-Nichols and experimental because it does not need high experience and complex calculations and leads to better results. This research develops nonlinear two-dimensional mathematical model to describe landing gear system with oleopneumatic shock absorber and linear tire. Based on this model, the dynamic equations are used to investigate the behavior of an aircraft semi-active landing gear system subject to runway disturbance excitation and the stability conditions of the landing system around static equilibrium position is studied. SIMULINK simulation software is applied to validate the theoretical analysis of system stability. Results of system numerical Simulation with optimized controller using Bees Algorithm in MATLAB software shows that the transmitted impact load to airframe, the vertical vibration of aircraft and time to return static equilibrium position at touchdown are significantly improved.
\end{abstract}

\section{General Terms}

Classical Technique, Optimization Algorithm

\section{Keywords}

Aircraft Semi-Active Suspension System, PID Technique, Bees Intelligent Algorithm

\section{INTRODUCTION}

An aircraft landing gear system must absorb the kinetic energy produced by a landing impact and excitations caused by the aircraft travelling over an uneven runway surface. This is the necessary requirement of a successfully designed landing system [1-2]. The oleo-pneumatic shock strut is the most common type of shock absorber landing gear system used in aircrafts. It dissipates the kinetic energy produced by impacts arising when an airplane lands at high speed but also offers a comfortable ride to passengers when the airplane taxies at low speed. The strut behaves in a strongly nonlinear manner, which affects the performance of the landing system [3-5]. From 1970s, the active control and semi-active control began to be popular and widely used in vibration control of constructions and vehicle suspensions. Compared with the passive control, the active and semi-active controls have excellent tunabilities due to their flexible structure. The main drawback of an active control approach is that its structure is rather complex and the external energy may lead to instability of the system. The semi-active approach modifies the damping charactristics by changing the size of the orifice area and does not introduce any external energy. Studies of Karnopp [6] for automotive applications also suggest that the efficiency of semi-active damper is only marginally lower than that of a fully active system, provided that a suitable control concept is used. In consideration of its structural simpleness and trustiness, a semi-active control approach could be a better choice for landing gear suspension system.

Kruger [7] focuses his research on optimization of taxiing performance of a semi-active landing gear. SIMPACK multibody software is used to run simulations with a complete aircraft FEA model. Maemori [8] proposes an optimization method for a semi-active landing gear to handle variations in the maximum vertical acceleration of an aircraft during landing caused by the variation of the aircraft mass. Ghiringhelli [9] builds a complete aircraft landing simulation model in ADAMS software. A semi-active PID control method is used to control the orifice area. Sensitivity test on the controller is conducted using the multibody drop test models and results obtained in the simulated drop tests with different configurations are compared. And he also evaluates the operating possibilities of semi-active control for a general aviation aircraft [10]. Wang [11] considers both taxiing and landing impact conditions. A fuzzy controller is developed to optimize the performance of the semi-active landing gear. But his control algorithm is in continuous form, which is not feasible in practical systems where the control rate and magnitude of the valve are limited. Dong-su [12] constructs a semi-active GA-besed nonlinear model predictive controller for landing gear system at touchdown. Drop tests are carried out on an experimental passive landing gear systerm to validate the parameters of the simulation model. The result of numerical simulation shows that the isolation of impact load at touchdown can be significantly improved compared to other control algorithms. J.T. Xing [13] developes a mathematical model to control aircraft vibrations caused by runway excitation using an active landing gear system and focuses his paper on optimization of the performance of the active landing gear system. MATLAB simulation software is used to run simulations using a PID strategy.

The reminder of this paper is organized as follows: In section 2 , the model of semi-active landing gear is introduced. Then in section 3, PID control technique and Bees intelligent optimization algorithm is developed. Section 4 presents stability analysis of system. In section 5 , the numerical 
simulation is performed and the conclusion of this investigation is summarized in sections 6 .

\section{MODEL OF SEMI-ACTIVE LANDING GEAR SYSTEM}

Semi-active control is the combination of passive control and a computer controlled servo valve. If the valve fails, the semiactive system will be a traditional passive system. So high reliability is one of the basic characteristics of semi-active control system. Figure 1 shows the basic structure of a semiactive shock absorber in a landing gear [12]. Figure 2 is the model of a semi-active landing gear [12]. The structure mass of landing gear is divided into sprung mass and non-sprung mass. Sprung mass defined in the model includes the airframe, the cylinder etc. Non-sprung mass includes the piston, wheel etc. Figure 3 represents the model of semiactive landing gear with semi-active control unit.

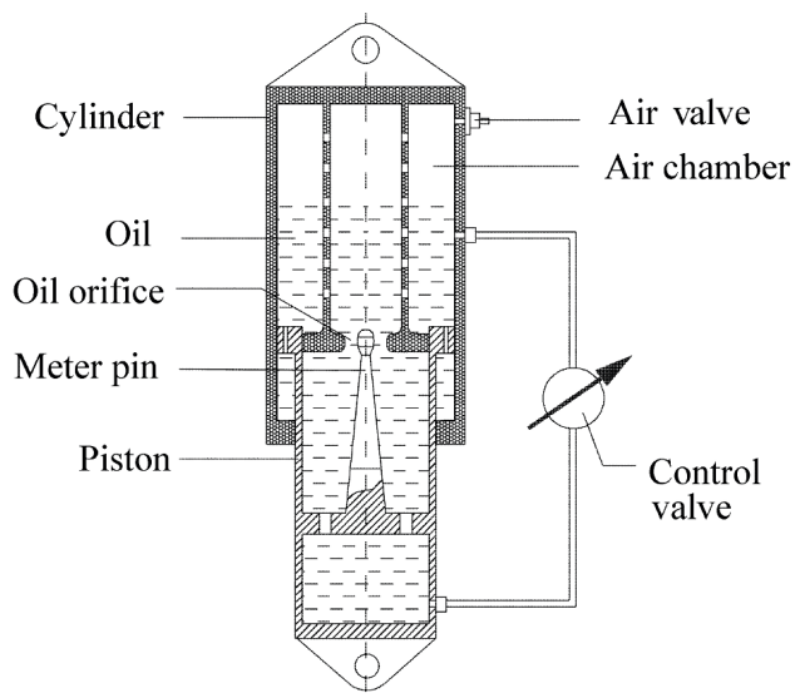

Fig 1. Structure of semi-active controlled shock absorber

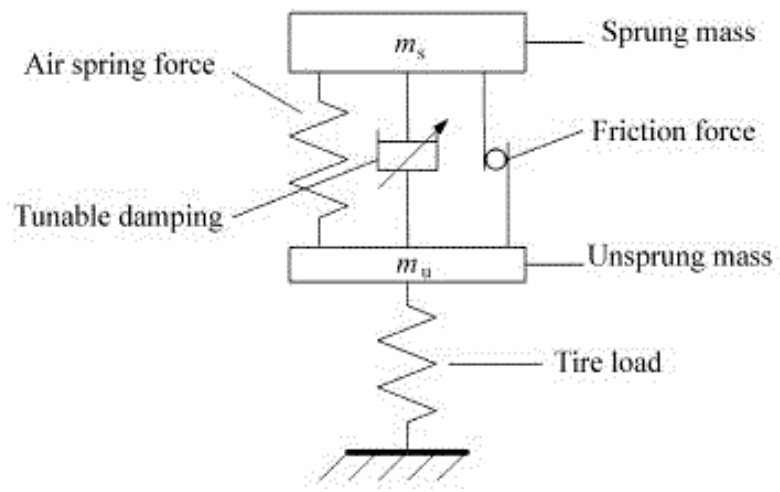

Fig 2. System model of semi-active landing gear

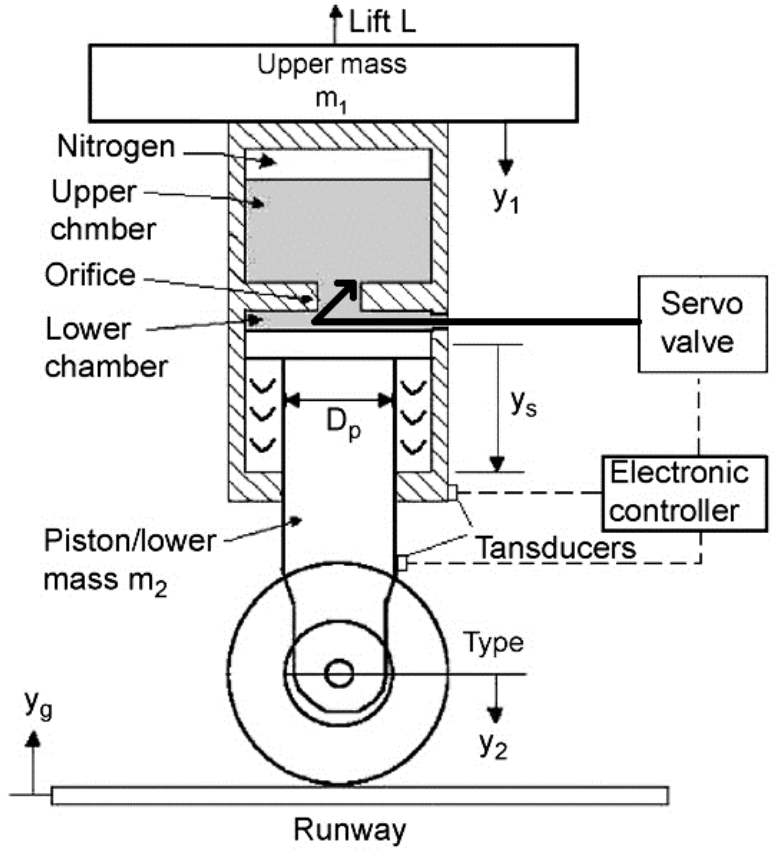

Fig 3. Model of semi-active landing gear with semiactive control system

\subsection{Dynamic Equilibrium Equations}

Using Newton's second law of motion and the system model in Figure 3, we represent the dynamic equilibrium equations as

$$
\begin{aligned}
& m_{1} \ddot{y}_{1}=m_{1} g-L-F_{a}-F_{o}-f \\
& m_{2} \ddot{y}_{2}=m_{2} g-F_{t}+F_{a}+F_{o}+f
\end{aligned}
$$

\subsection{Shock Strut Force}

Considering principles of the shock strut operation, a damping effect is produced by pressing the compressed oil through the tunable orifice. It produces an oleo damping force. In the pneumatic chamber, the air is compressed by the movement of the piston, thus it provides an air spring force. Additional friction forces experienced by the landing gear are generated from two principal sources. Namely, one force is caused by the tightness of the seal and the other friction force is due to the offset wheel.

\subsubsection{Oleo Damping Force}

$$
F_{o}=\frac{\rho A^{3}}{2 C_{o}^{2} A_{o}^{2}}\left(\dot{y}_{1}-\dot{y}_{2}\right)^{2} \operatorname{sgn}\left(\dot{y}_{1}-\dot{y}_{2}\right)
$$




\subsubsection{Air Spring Force}

$$
F_{a}=P_{0} A\left(1-\frac{y_{1}-y_{2}}{y_{0}}\right)^{-n}
$$

\subsubsection{Friction Force}

$$
\begin{aligned}
& f=f_{\text {seal }}+f_{\text {ow }}=k_{m}\left(\dot{y}_{1}-\dot{y}_{2}\right)+ \\
& \operatorname{sgn}\left(\dot{y}_{1}-\dot{y}_{2}\right) k_{n}\left(\dot{y}_{1}-\dot{y}_{2}\right)^{2}+\mu\left(\frac{F_{t} L}{y_{1}-y_{2}+B}\right)
\end{aligned}
$$

\subsection{Tire Force}

In order to simplify the mathematical model, the tire is acted as a combination of a linear spring and a linear damper as follows [21]:

$$
F_{t}=c_{t}\left(\dot{y}_{2}+\dot{y}_{g}\right)+k_{t}\left(y_{2}+y_{g}\right)
$$

\section{CONTROLLER DESIGN}

Classical controller accounts for more than $90 \%$ of the controls and automation applications today, primarily because effective and simple to implement.

\subsection{Introduction of PID Controller}

Proportional Integral Derivative Controller (PIDC) is used where system is second-order or high order. It ensures setpoint tracking with zero steady state error and allows faster response without oscillatory nature of PI control greater influence of error response, degree of overshoot and oscillation.

The oil orifice area of servo valve is controlled by classical method as shown in figure 4. This classical controller has the advantage of being structurally simple, mathematically credible, more or less easy to realize with scope for adjustment, thus making it widely applicable in engineering systems [14]. This control method is chosen to complete the mathematical model and to investigate the landing gear system's performance.

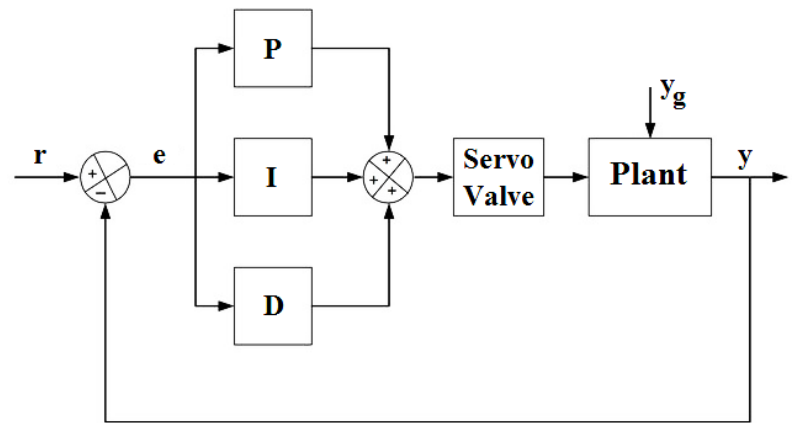

Fig. 4: Schematic sketch of the PID classical controller

In Figure 4, $\mathrm{r}$ represents a reference signal and $\mathrm{y}$ is the feedback signal measured from the landing gear by transducers. Their difference e is input into the classical controllers. The transfer functions of PID controller is defined as follows:

$$
C(s)=\frac{U(s)}{E(s)}=k_{p}+\frac{k_{i}}{s}+k_{d} s
$$

$\mathrm{k}_{\mathrm{p}}$ represents a proportionality coefficient, $\mathrm{k}_{\mathrm{i}}$ an integral coefficient and $\mathrm{k}_{\mathrm{d}}$ a differentional coefficient. These feedback coefficients can be adjusted to obtain the best control efficiency. The output signal of the controller gives the tunable oil orifice area of servo valve as follows

$$
A_{o}(t)=k_{p}\{\dot{r}(t)-\dot{y}(t)\}+k_{i}\{r(t)-y(t)\}+k_{d}\{\ddot{r}(t)-\ddot{y}(t)\}
$$

\subsection{Introduction of Bees Algorithm}

There is an algorithm which works similar to the Bees Algorithm [15]. Figure 5 shows the flowchart of Bees Algorithm. For more details, the reader is referred to [16]. The algorithm requires a number of parameters to be set, namely: number of scout bees (n), number of sites selected for neighborhood searching (out of $n$ visited sites) (m), number of top-rated (elite) sites among $\mathrm{m}$ selected sites (e), number of bees recruited for the best e sites (nep), number of bees recruited for the other (m-e) selected sites (nsp), the initial size of each patch (ngh) (a patch is a region in the search space that includes the visited site and its neighborhood), and the stopping criterion. Figure 6 represents schematic sketch of the classical controller with Bees Algorithm. The objective function of optimization problem is introduced in Equation 8.

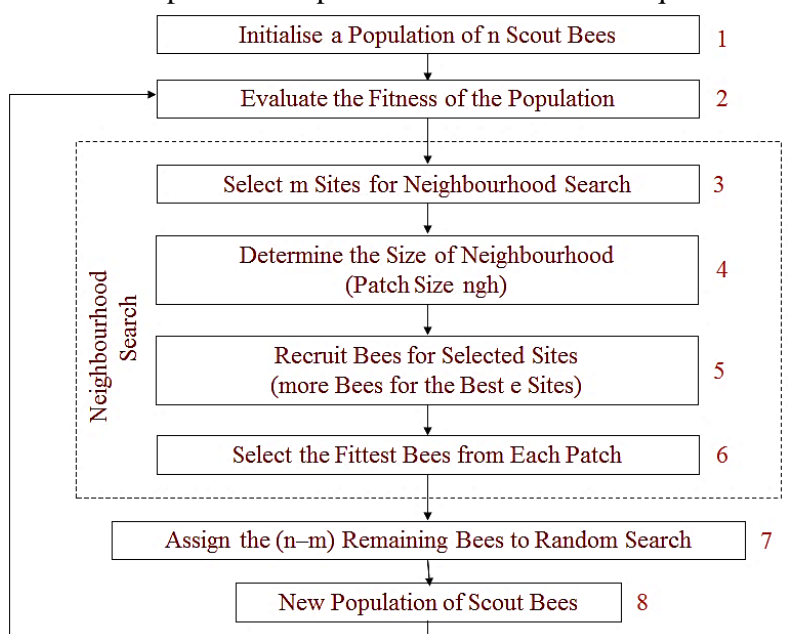

Fig. 5: Flowchart of the Bees Algorithm (BA)

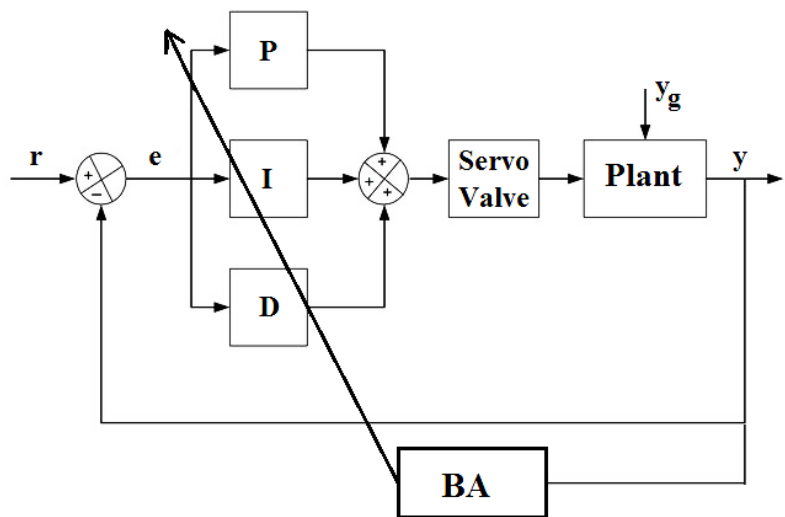

Fig. 6: Schematic sketch of the PID-BA controller

$I T A E=\int_{0}^{T} t|e(t)| d t$ 


\section{STABILITY ANALYSIS}

We assume that, in time, the aircraft returns to its static equilibrium position after a landing impact or a runway excitation. A passive landing gear satisfies this assumption. Semi-active landing system is established by using of semiactive control unit. This unit provides adjustable damping to improve the performance of the passive landing gear system. It plays a modifying role with the expectation that they cause the aircraft to return to its static equilibrium position quicker than by the passive landing gear system.

\subsection{Static Equilibrium Solution}

To determine the static equilibrium solution of the landing gear system, the time derivatives of the displacements $y_{1}$ and $\mathrm{y}_{2}$, the ground inputs and its time derivative are set to zero [18]. This allows Equation 1 reduces to

$$
\begin{aligned}
& m_{1} \ddot{y}_{1}=-F_{a}-F_{o}-f \\
& m_{2} \ddot{y}_{2}=-F_{t}+F_{a}+F_{o}+f
\end{aligned}
$$

\subsection{Dynamic Equations around the Static Equilibrium Solution}

By using Taylor's expansion around static stroke of shock absorber and neglecting higher-order quantities [18], the term arising Equation 9 is derived as follow

\subsubsection{Air Spring Force}

$F_{a}=p_{0} A\left(\frac{n}{y_{0}}\right)\left(y_{1}-y_{2}\right)$

\subsubsection{Friction Force}

$$
f=k_{m}\left(\dot{y}_{1}-\dot{y}_{2}\right)
$$

\subsection{Stability Condition}

By substitution of linearised Equations in Equation 9 and taking Laplace transform, the transfer functions of system are derived as follow

$$
\begin{aligned}
& G_{1}(s)=\frac{y_{1}(s)-y_{2}(s)}{y_{g}(\mathrm{~s})}=\frac{m_{1} c_{t} s^{3}+m_{1} k_{t} s^{2}}{a_{4} s^{4}+a_{3} s^{3}+a_{2} s^{2}+a_{1} s+a_{0}} \\
& G_{2}(s)=\frac{y_{1}(s)-y_{2}(s)}{F_{O}(\mathrm{~s})}=\frac{-\left(m_{1}+m_{2}\right) s^{2}-c_{t} s-k_{t}}{a_{4} s^{4}+a_{3} s^{3}+a_{2} s^{2}+a_{1} s+a_{0}}
\end{aligned}
$$

Where,

$$
\begin{aligned}
& a_{4}=m_{1} m_{2} \\
& a_{3}=c_{t} m_{1}+k_{m}\left(m_{1}+m_{2}\right) \\
& a_{2}=c_{t} k_{m}+k_{t} m_{1}+p_{0} A\left(\frac{n}{y_{0}}\right)\left(m_{1}+m_{2}\right) \\
& a_{1}=\mathrm{c}_{t} p_{0} A\left(\frac{n}{y_{0}}\right)+k_{t} k_{m} \\
& a_{0}=k_{t} p_{0} A\left(\frac{n}{y_{0}}\right)
\end{aligned}
$$

According to the Routh-Hurwitz stability criterion [17], the conditions for stability are achieved from equations 14 and 15 as follow

$$
\begin{aligned}
& C(s) \cdot G_{1}(\mathrm{~s})=-1 \\
& \frac{K_{p} s+K_{i}+K_{d} s^{2}}{s} \cdot \frac{\left(m_{1} c_{t} s^{3}+m_{1} k_{t} s^{2}\right)}{a_{4} s^{4}+a_{3} s^{3}+a_{2} s^{2}+a_{1} s+a_{0}}=-1 \\
& K_{d}>\min \left\{\frac{-a_{4}}{m_{1} c_{t}}, \frac{-a_{3}}{m_{1} k_{t}}\right\} \\
& K_{p}>\min \left\{\frac{-a_{3}}{m_{1} c_{t}}, \frac{-a_{2}}{m_{1} k_{t}}\right\} \\
& K_{i}>\min \left\{\frac{-a_{2}}{m_{1} c_{t}}, \frac{-a_{1}}{m_{1} k_{t}}\right\}
\end{aligned}
$$

$$
\begin{aligned}
& C(s) \cdot G_{2}(\mathrm{~s})=-1 \\
& \frac{K_{p} s+K_{i}+K_{d} s^{2}}{s} \cdot \frac{-\left(m_{1}+m_{2}\right) s^{2}-c_{t} s-k_{t}}{a_{4} s^{4}+a_{3} s^{3}+a_{2} s^{2}+a_{1} s+a_{0}}=-1 \\
& K_{d}<\max \left\{\frac{a_{3}}{\left(m_{1}+m_{2}\right)}, \frac{a_{2}}{c_{t}}, \frac{a_{1}}{k_{t}}\right\} \\
& K_{p}<\max \left\{\frac{a_{2}}{\left(m_{1}+m_{2}\right)}, \frac{a_{1}}{c_{t}}, \frac{a_{0}}{k_{t}}\right\} \\
& K_{i}<\max \left\{\frac{a_{1}}{\left(m_{1}+m_{2}\right)}, \frac{a_{0}}{c_{t}}, 0\right\}
\end{aligned}
$$

\section{NUMERICAL SIMULATION}

SIMULINK control system simulation software derives numerical simulations of the semi-active landing gear system responses. We investigate A6 Intruder airplane [13] with values according to Table 1 and Parameters of the Bees Algorithm are given in Table 2. Aircraft and Landing gear masses are $4832.7 \mathrm{~kg}$ and $145.1 \mathrm{~kg}$, respectively. Lift Aerodynamic Force is $7500 \mathrm{~N}$ and runway disturbance is half sin-type ramp of height $10 \mathrm{~cm}$ and time $0.4 \mathrm{~s}$ over which the airplane travels. The parameters defining the stability conditions are given by

$$
\left\{\begin{array}{c}
k_{p}<1.680 \\
1.23 \times 10^{-5}<k_{i}<1.601 \\
k_{d}<1.042
\end{array}\right.
$$

TABLE 1: Data used in the simulation

\begin{tabular}{|c|c|c|c|}
\hline Shock Absorber & Value & Tyre & Value \\
\hline $\begin{array}{c}\text { Initial pressure, } \\
\mathbf{P}_{\mathbf{0}}(\mathbf{p a})\end{array}$ & $1.6 \mathrm{e}+06$ & $\begin{array}{c}\text { Stiffness } \\
\text { coefficient, } \\
\mathrm{k}_{\mathrm{t}}(\mathrm{N} / \mathrm{m})\end{array}$ & $1.5 \mathrm{e}+06$ \\
\hline $\begin{array}{c}\text { Initial volume, } \\
\mathbf{V}_{\mathbf{0}}\left(\mathbf{m}^{\mathbf{3}}\right)\end{array}$ & $6.88 \mathrm{e}-03$ & $\begin{array}{c}\text { Damp } \\
\text { coefficient, } \\
\mathrm{c}_{\mathrm{t}}(\mathrm{Ns} / \mathrm{m})\end{array}$ & $2.6 \mathrm{e}+06$ \\
\hline $\begin{array}{c}\text { Effective area, } \mathbf{A} \\
\left(\mathbf{m}^{\mathbf{2}}\right)\end{array}$ & $1.376 \mathrm{e}-02$ & --- & --- \\
\hline $\begin{array}{c}\text { Orifice area, } \mathbf{A}_{\mathbf{O}} \\
\left(\mathbf{m}^{\mathbf{2}}\right)\end{array}$ & $6.412 \mathrm{e}-04$ & --- & --- \\
\hline
\end{tabular}




\begin{tabular}{|c|c|c|c|}
\hline $\begin{array}{c}\text { Density, } \rho \\
\left(\mathrm{kg} / \mathrm{m}^{3}\right)\end{array}$ & 912 & --- & --- \\
\hline $\begin{array}{l}\text { Flow coefficient, } \\
\mathrm{C}_{0}\end{array}$ & 0.3 & --- & --- \\
\hline $\begin{array}{c}\text { Coefficient of } \\
\text { kinetic friction, } \\
k_{m}(\mathrm{Ns} / \mathrm{m})\end{array}$ & $0.7 e+04$ & --- & --- \\
\hline $\begin{array}{c}\text { Coefficient of } \\
\text { kinetic friction, } \\
k_{n}(\mathrm{Ns} 2 / \mathrm{m} 2)\end{array}$ & $0.1 e+05$ & --- & --- \\
\hline Gas constant, $n$ & 1.1 & --- & --- \\
\hline $\begin{array}{c}\text { Gravity } \\
\text { constant, } g\left(\mathrm{~m} / \mathrm{s}^{2}\right)\end{array}$ & 9.8 & --- & --- \\
\hline
\end{tabular}

TABLE 2: Data used in the Bees Algorithm

\begin{tabular}{|c|c|}
\hline Case 1 (without runway disturbance) & Value \\
\hline N & 150 \\
\hline M & 20 \\
\hline E & 5 \\
\hline Nep & 15 \\
\hline Nsp & 10 \\
\hline Ngh & 40 \\
\hline Case 2 (with runway disturbance) & Value \\
\hline N & 120 \\
\hline M & 12 \\
\hline E & 8 \\
\hline Nep & 18 \\
\hline Nsp & 5 \\
\hline Ngh & 80 \\
\hline
\end{tabular}

\subsection{RESULTS AND DISCUSSIONS}

Three kinds of control methods including passive control, PID based on experiment and PID based on Bees Algorithm adopting a wide range of control parameters for semi-active control in two cases (without disturbance and with disturbance) are used in the computer simulation. In the process of simulation, the comparison is taken in terms of different sinking speed: $3 \mathrm{~m} / \mathrm{s}$ (light landing), $4 \mathrm{~m} / \mathrm{s}$ (normal landing) and $5 \mathrm{~m} / \mathrm{s}$ (hard landing).

\subsubsection{Case 1: Results without Runway} Disturbance

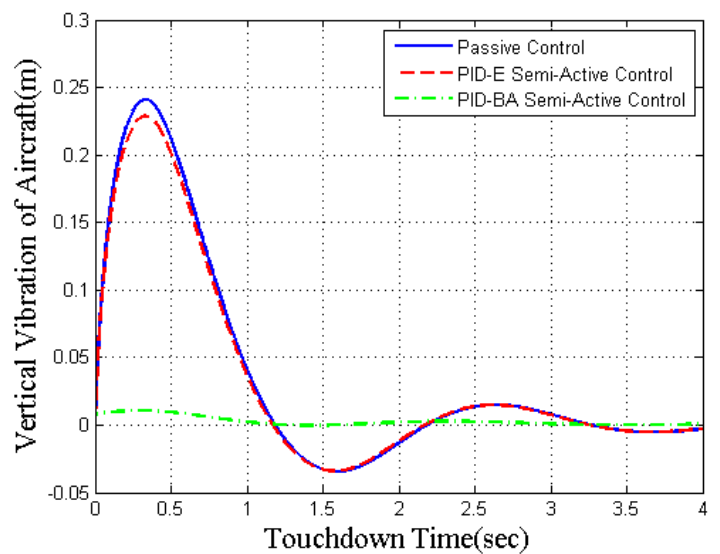

Fig 7. Vertical vibration of aircraft for light landing

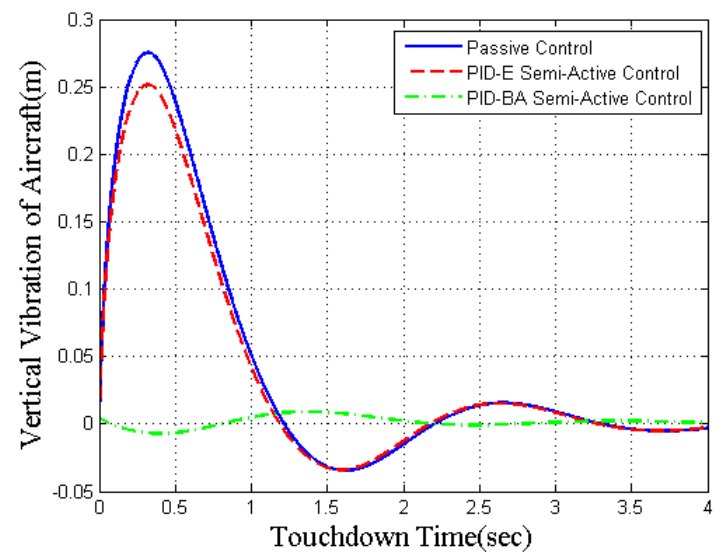

Fig 8. Vertical vibration of aircraft for normal landing

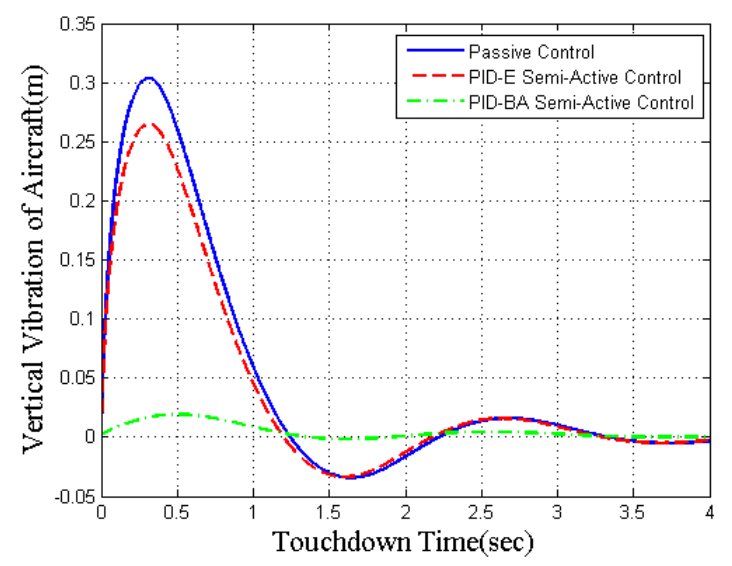

Fig 9. Vertical vibration of aircraft for hard landing

The vertical displacement of the aircraft is an important parameter in designing an aircraft landing gear system. It is expected that an aircraft rapidly returns to its original equilibrium state without runway disturbance. Through numerical simulation and according to the parameters defining the stability conditions, we found that the approximate optimum set in Bees Algorithm produced the best control efficiency. Figures 7 and 8 and 9 show that there is $80 \%$ and $85 \%$ and $90 \%$ decrease of the aircraft's displacement response, respectively, making taxiing smoother and therefore the crew/passenger comfort improved. The passive system requires approximately $3 \mathrm{~s}$ for the aircraft to return to its static equilibrium position. This time is reduced to approximately $1 \mathrm{~s}$ using semi-active system with PID controller and Bees Algorithm that demonstrates a significant improvement over the performance of the passive system. 


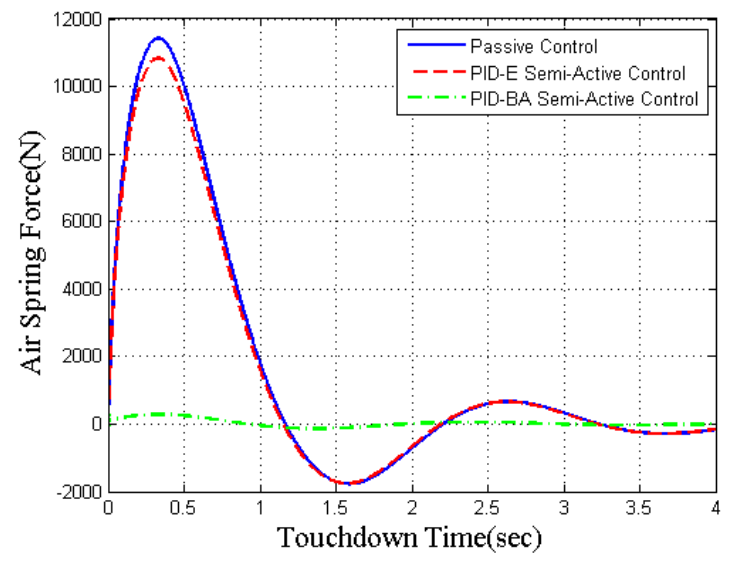

Fig 10. Air spring force for light landing

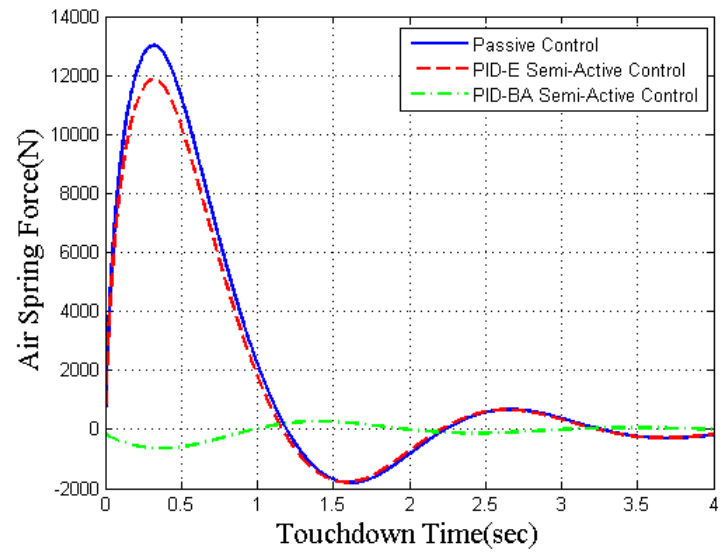

Fig 11. Air spring force for normal landing

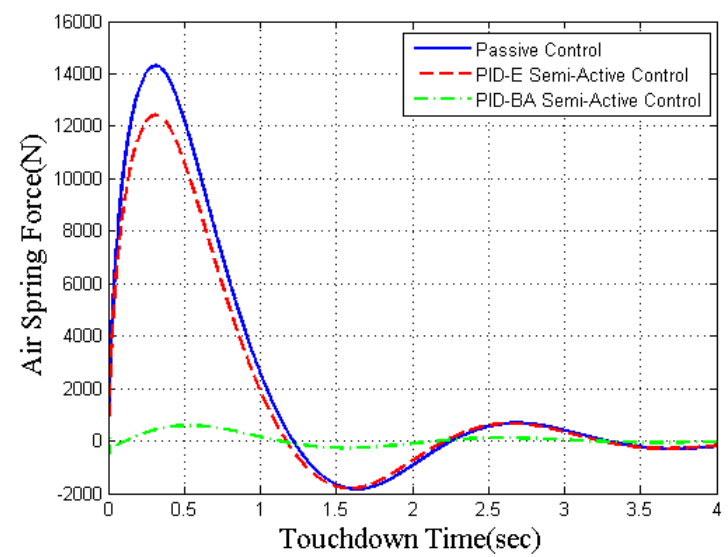

Fig 12. Air spring force for hard landing

The amplitude of the spring force transmitted to the airframe and landing gear affects the structural strength and the fatigue life of them. Figures 10 and 11 and 12 show that this force is reduced using the PID-BA active system and indicate that there is $80 \%$ and $85 \%$ and $90 \%$ decrease of the transmitted force in the passive landing gear respectively, if this system is used that results in improvements to the longevity of the airframe and landing gear and comfort to passengers

\subsubsection{Case 2: Results with Runway Disturbance}

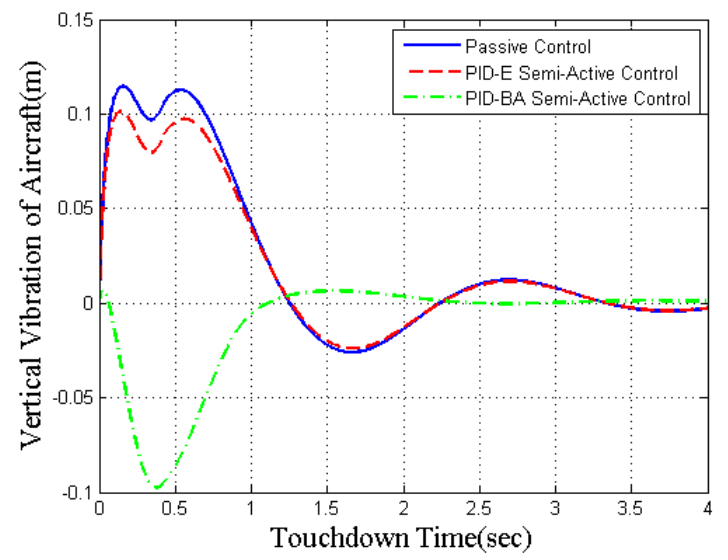

Fig 13. Vertical vibration of aircraft for light landing

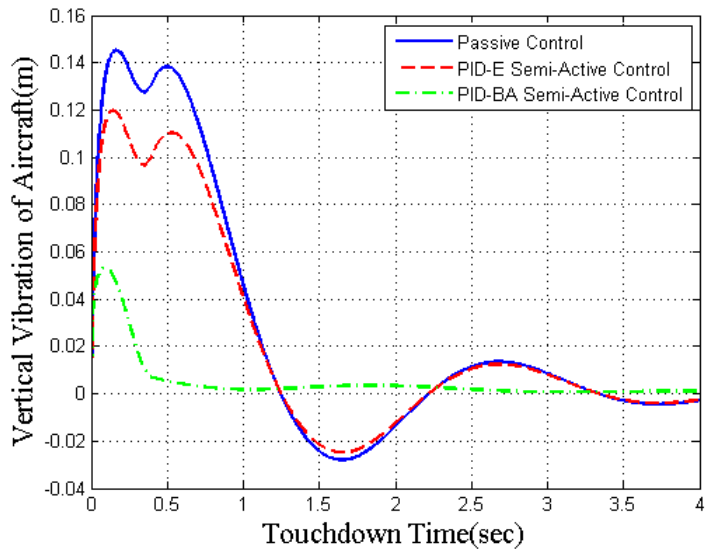

Fig 14. Vertical vibration of aircraft for normal landing

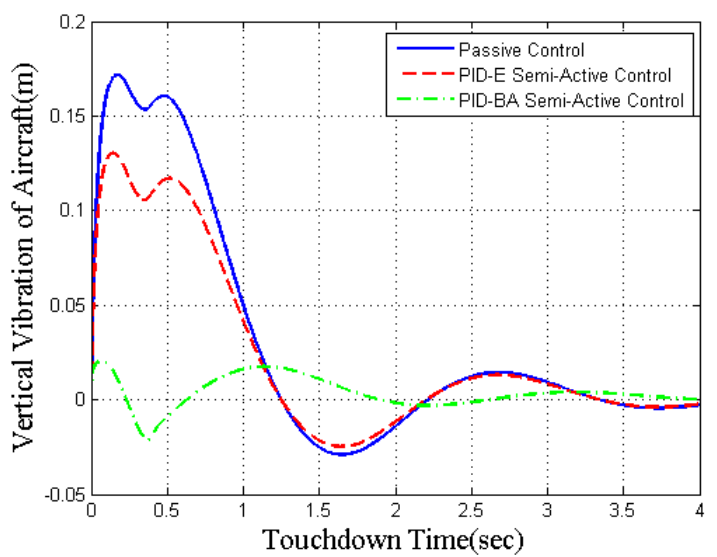

Fig 15. Vertical vibration of aircraft for hard landing The vertical displacement of the aircraft is an important parameter in designing an aircraft landing gear system. It is expected that an aircraft rapidly returns to its original equilibrium state when influenced by a runway disturbance. Through numerical simulation and according to the parameters defining the stability conditions, we found that the approximate optimum set in Bees Algorithm produced the best control efficiency. Figures 13 and 14 and 15 show that there is $16 \%$ and $66 \%$ and $82 \%$ decrease of the aircraft's displacement response, respectively, making taxiing smoother and therefore the crew/passenger comfort improved. The 
passive system requires approximately $3 \mathrm{~s}$ for the aircraft to return to its static equilibrium position. This time is reduced to approximately $2 \mathrm{~s}$ using active system with PID controller and Bees Algorithm that demonstrates a significant improvement over the performance of the passive system.

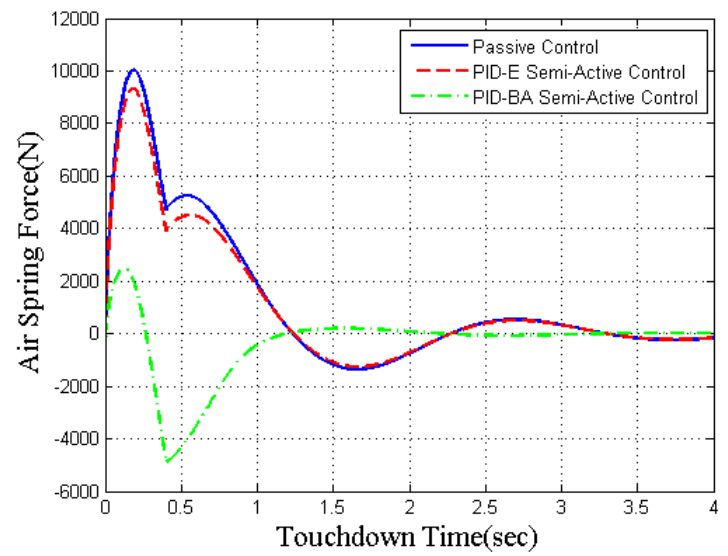

Fig 16. Air spring force for light landing

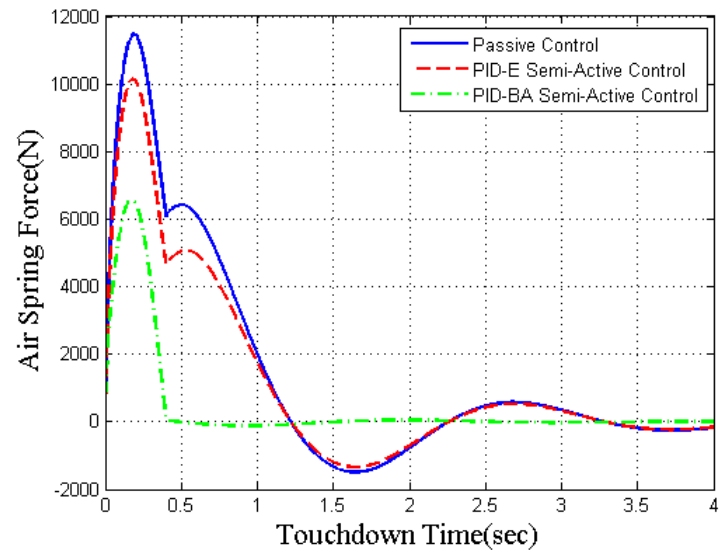

Fig 17. Air spring force for normal landing

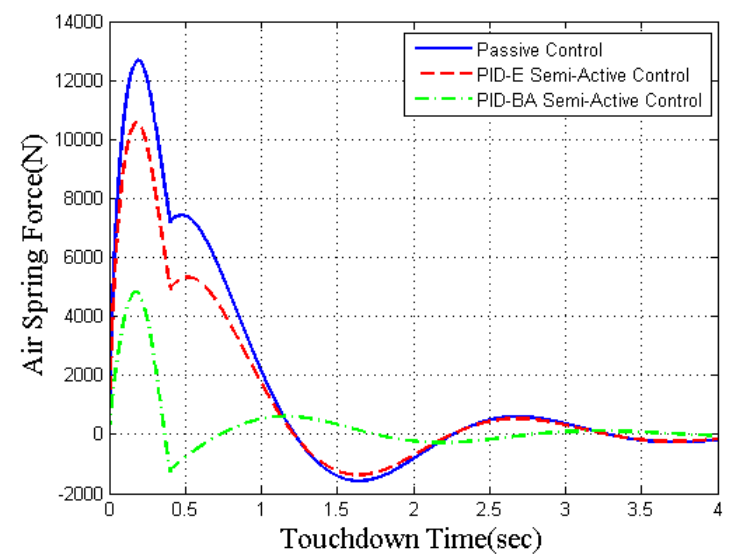

Fig 18. Air spring force for hard landing

The amplitude of the spring force transmitted to the airframe and landing gear affects the structural strength and the fatigue life of them. Figures 16 and 17 and 18 show that this force is reduced using the PID-BA active system and indicate that there is $80 \%$ and $45 \%$ and $66 \%$ decrease of the transmitted force in the passive landing gear respectively, if this system is used that results in improvements to the longevity of the airframe and landing gear and comfort to passengers.

\section{CONCLUSION}

The nonlinear features of the mathematical model describing the semi-active landing gear system and control method of the tunable orifice area of servo valve are major challenges to design of a controller. In this paper, PID-Bees Algorithm control strategy for semi-active landing gear at touchdown with vertical displacement of aircraft optimization objective is proposed. It is shown that the maximal overshoot of aircraft and structural load induced by the landing impact can be significantly absorbed and it can be concluded that the overall efficiency of the semi-active landing gear is increased. This study provides a theoretical and numerical approach to initiate the design of a realizable semi-active landing gear system. The linearized equations are used here to study the stability of a nonlinear system about static equilibrium point.

\section{REFERENCES}

[1] N.S. Currey, "Aircraft landing gear design: principles and practices, AIAA Education Series, AIAA (1998).

[2] R. Freymann, “Actively damped landing gear system, Landing Gear Design Loads Conference, No.20, AGARD CP-484, 1991.

[3] R. Freymann, "An experimental-analytical routine for the dynamic qualification of aircraft operating on rough runway surfaces, AGARD R-731 (1987).

[4] T. Catt, D. Cowling, A. Shepherd, "Active landing gear control for improved ride quality during ground roll, SDL Report No. 232, Stirling Dynamics Limited, 1992.

[5] T.W. Lee, "Dynamic response of landing gears on rough repaired runway, Menasco Aero Systems Division (1998) 124-135.

[6] Karnopp D. "Active damping in road vehicle suspension systems. Vehicle System Dynamics, 1983. 12(6):291-316.

[7] Wolf K. "Integrated design process for the development of semi- active landing gears for transport aircraft. Germany Universität Stuttgart, 2000.

[8] Maemori K, Tanigava N, Koganei R, et al. Optimizattion of a semi-active shock absorber for aircraft landing gear. Proceedings of the ASME Design Engineering Technical Conference, 2003. 2A:597-603.

[9] Ghiringhelli L G, Gualdi S. Evaluation of a landing gear semi-active control system for complete aircraft landing. Aerotechnica Missili e Spazio 2004; 83:21-31.

[10] Gheringhelli L G. Testing of semi-active landing gear control for a general aviation aircraft. Journal of Aircraft 2000; 7(4):606-616.

[11] Wang X M, Carl U. Fuzzy control of aircraft semi-active land- ing gear system. AIAA 99-0265, 1999.

[12] WU Dong-su, GU Hong-bin, LIU Hui. GA-Based Model Predictive Control of Semi-Active Landing Gear. Chinese Journal of Aeronautics 20(2007) 47-54.

[13] Haitao Wang, J.T. Xing, W.G. Price, Weiji Li. An investigation of an active landing gear system to reduce airceaft vibeations caused by landing impacts and 
runway excitations. Journal of Sound and Vibration 317(2008)50-66.

[14] A. Datta, M.T. Ho, S.P. Bhattacharyya, Structureand Synthesis of PID Controllers, Springer, London, 2000.

[15] Karaboga D. An Idea Based on Honey Bee Swarm for Numerical Optimization. Turkiye: Erciyes University, Engineering Faculty, Computer Engineering Department. Technical Report. TR06.2005
[16] Pham D.T., Ghanbarzadeh A., Koc E., Otri S., Rahim S., and Zaidi M. The Bees Algorithm. Cardiff: Manufacturing Engineering Centre, Cardiff University.Technical Report. MEC 0501.2005

[17] A. Hurwitz, On the condition under which an equation has only roots with negative real part, in: R. Bellman, R. Kalaba (Eds.),Selected Papers on Mathematical Trends in Control Theory, Dover, New York, 1964, pp. 72-82. 